\title{
Experimental Studies on Effects of Sodium Citrate, Calcium Nitrite and Hexamine as Corrosion Inhibitor in Concrete
}

MA Quraishi*, DK Nayak², BN Singh², V Kumar² and KK Pandey²

${ }^{1}$ Department of Applied Chemistry, Indian Institute of Technology, Banaras Hindu University, Varanasi, India

${ }^{2}$ Department of Civil Engineering, Indian Institute of Technology, Banaras Hindu University, Varanasi, India

\begin{abstract}
In the present study the effect of sodium citrate, calcium nitrate, and hexamine on corrosion of steel was analyzed. The effect of inhibitor on normal consistency of cement, initial and final setting time of cement, compressive strength of cement, soundness of cement and compressive strength of concrete were also analyzed. The results of the study also concluded that hexamine and calcium nitrite are more efficient inhibitor. It showed $45 \%$ and $25 \%$ inhibitor efficiency at the denseness of $0.5 \%$ hexamine and $0.5 \%$ calcium nitrite by weight of cement respectively. Further, sodium citrate also prevents the hydration of cement, but it is not suitable as an inhibitor. The addition of Inhibitor acts as retarder for the initial and final setting period of the cement and retard the compressive strength at initial days. After 180 days strength is improved significantly.
\end{abstract}

Keywords: TMT steel; Hexamine; Sodium citrate; Calcium nitrite; Corrosion inhibition; Petrographic studies

\section{Introduction}

Concrete would not have gained its present status as a principal building material, but for the invention of reinforced concrete, which is concrete with steel bar embedded in it. The idea of reinforcing concrete with steel has resulted in a new composite material, having the ability to resist significant tensile stresses as well, which was otherwise impossible. However, failures in the structures occur as a result of premature reinforcement corrosion [1,2]. It has become a serious, problem worldwide, with costly repairs now in billions of dollars annually. In addition, the numerous intangible losses such as the energy needed to manufacture the replacements of corroded objects. The havoc spread by corrosion is infamous. The economic loss and damage caused by the corrosion of steel in concrete makes it arguably the largest single infrastructural problem of industrialized countries. All of these have tended to focus attention on techniques for inhibiting corrosion in concrete. The use of corrosion inhibitors is most attractive from the viewpoint of ease of application and economy, among the widely available methods to prevent corrosion in concrete [3-5]. There are many studied done on the use of inhibitors of corrosion of steel [6-12]. Widely used industrial inhibitors either show toxic or show adverse effects on the concrete properties. Environmental legislations have also restricted the use of several inhibitors. Therefore, green inhibitors have become the need of the hour. In the sequence of our work on the development of inhibitors [13-17], inhibiting effects of the hexamine, calcium nitrite and sodium citrate on corrosion of steel in $3.5-4.5 \mathrm{pH}$ solutions are reported here in this report.

\section{Experimental}

Material used: OPC cement conforming to Indian Standard: 8112-1983 [18] fine aggregate having a fineness modulus 2.67, coarse aggregate having size of $10 \mathrm{~mm}$ of fineness modulus of 6.0 and $20 \mathrm{~mm}$ of fineness modulus of 7.44. Mortar was prepared using tap water. Tata Tiscon TMT steel bar was used for casting steel embedded concrete cubes. For corrosion in steel bars Acid water having a $\mathrm{pH}$ range of 3.5 - 4.5. $\left(\mathrm{H}_{2} \mathrm{SO}_{4}: \mathrm{HNO}_{3}=0.5: 1.0\right)$ was used in the study. Sodium citrate, calcium nitrite and hexamine were used as an inhibitor.

Corrosion Test: Prismatic cubes of concrete having dimensions 10 $\mathrm{cm} \times 10 \mathrm{~cm} \times 10 \mathrm{~cm}$ by keeping the cover of $2.5 \mathrm{~cm}$ on each side in lengthwise were prepared, embedding $5 \mathrm{~cm}$ length in the cube using $0.8 \mathrm{~cm} ø$ TMT steel bars. The weight of each steel bar was measured in grams upto three digits after the decimal. Moulds were removed after $24 \mathrm{hrs}$ of casting and then the samples were kept in water having a $\mathrm{pH}$ of 3.5 to 4.5 for 90 days and 180 days. After that samples were taken out and dried. Then the samples were broken using UTM and embedded steel bars were taken out and cleaned in Clarke's solution (1 ltr. conc. $\left.\mathrm{HCl}+20 \mathrm{~g}\left(\mathrm{Sb}_{2} \mathrm{O}_{3}\right)+50 \mathrm{~g}\left(\mathrm{SnCl}_{2}\right)\right)$. Finally, samples were washed with distilled water. Sample steel bars were then dried and weighed. The efficiency of the inhibitor was calculated using the following formula (1):

$$
\% \text { efficiency of inhibitor }=\left[\left(\mathrm{W}_{0}-\mathrm{W}\right) / \mathrm{W}_{0}\right] \times 100
$$

Where, $\mathrm{W}_{0}=$ Average final weight (in $\mathrm{mg}$ ) of steel embedded in the control sample

$\mathrm{W}=$ Average final weight (in $\mathrm{mg}$ ) of steel embedded in inhibited samples

Consistency of cement: Standard consistency of a cement paste is defined as that consistency which will permit a Vicat plunger having 10 $\mathrm{mm}$ dia and $50 \mathrm{~mm}$ length to penetrate to a depth of 33-35 $\mathrm{mm}$ from top of the mould conforming to Indian Standard: 4031 (Part 4)-1988 [19].

Initial and Final Setting time: Initial setting time is that time period between the time water is added to cement and time at which $1 \mathrm{~mm}$ square section needle fails to penetrate the cement paste, placed in the Vicat's mould $5 \mathrm{~mm}$ to $7 \mathrm{~mm}$ from the bottom of the mould. Final setting time is that time period between the time water is added

*Corresponding author: MA Quraishi, Department of Applied Chemistry, Indian Institute of Technology, Banaras Hindu University, Varanasi-221005, India, Tel: 0542236 8558; E-mail: maquraishi.apc@itbhu.ac.in

Received August 02, 2016; Accepted August 08, 2016; Published August 20, 2016

Citation: Quraishi MA, Nayak DK, Singh BN, Kumar V, Pandey KK (2016) Experimental Studies on Effects of Sodium Citrate, Calcium Nitrite and Hexamine as Corrosion Inhibitor in Concrete. J Steel Struct Constr 2: 117. doi: 10.4172/24720437.1000117

Copyright: () 2016 Quraishi MA, et al. This is an open-access article distributed under the terms of the Creative Commons Attribution License, which permits unrestricted use, distribution, and reproduction in any medium, provided the original author and source are credited. 
to cement and the time at which $1 \mathrm{~mm}$ needle makes an impression on the paste in the mould but $5 \mathrm{~mm}$ attachment does not make any impression. Conforming to Indian Standard: 8112-1989 [20].

Soundness test: Tests were performed according to Indian Standard: 4031(Part 3)-1988 [21].

Compressive strength of cement: Compressive strength of cement is determined by compressive strength test on mortar cubes compacted by means of a standard vibration machine. Standard sand (IS: 6501991) [22] is used for the preparation of cement mortar. Tests were performed according to Indian Standard: 4031(Part 6)-1988 [23]. The specimen is in the form of cubes $70.6 \mathrm{~mm} \times 70.6 \mathrm{~mm} \times 70.6 \mathrm{~mm}$.

Concrete cube specimen preparation: Representative samples of concrete shall be taken and used for casting cubes $15 \mathrm{~cm} \times 15 \mathrm{~cm} \times$ $15 \mathrm{~cm}$. The W/C ratio used was 0.5 for all samples. The inhibitor was mixed with cement at the respective percentage by weight of cement and then mixed inhibited cement was used to cast cement concrete cubes. The specimen was stored on site for $24+1 / 2 \mathrm{hr}$ under damp matting or sack. After that, the samples were stored in clean water at 27 $+2^{\circ} \mathrm{C}$; until the time of the test.

Petrographic test: Petrographic testing is the use of microscopes to examine samples of rock or concrete to determine their mineralogical and chemical characteristics. Petrographic examination can determine a range of parameters, as follows: Type, proportions, grading, shape and condition of the aggregates, nature of the cement paste, including mineral additions such as fly ash, the degree of hydration, presence of deleterious material, cement paste and air voids, depth of carbonation, bond between the aggregate and the paste evidence of sulfate attack, frost damage, some forms of chemical attack and alkali-silica reactions, depth of fire damage and temperature of the fire, measurement of air entrainment. It also helps in understanding of microstructural behavior and carbonation of building materials (like concrete etc.) [24].

\section{Results and Discussion}

In our current research, the inhibiting action of hexamine, calcium nitrite and sodium citrate on corrosion of steel in carbon environment was investigated. The mode of inhibiting action on soundness, consistency setting time of cement, comprehensive strength of cement and concrete was also studied. The analysis of the inhibiting systems is as follows (Table 1).

Consistency test of cement: The results of analysis of various samples of cement, reflects that "The appropriate amount of water to exhibit consistency is less in case of inhibited cement in comparison to plain cement sample (Table 2).

Soundness test: Results established "That the expansion was same for all samples i.e., inhibited and plain cement. So it can be concluded "That addition of inhibitor did not cause any change in volume after setting" and sample S-II disintegrated at the time of demolding (Table 3).

Setting time test: From Table 3 it is observed that calcium nitrite, hexamine and $0.5 \% \mathrm{SC}+0.5 \% \mathrm{CN}$ act as retarders. After comparing the

\begin{tabular}{|l|c|}
\hline Description of Sample & Notation \\
\hline Cement (Blank) & S-I \\
\hline $\begin{array}{l}\text { Cement }+0.5 \text { Calcium nitrite }+0.5 \% \text { Sodium citrate (by } \\
\text { weight of cement) }\end{array}$ & S-II \\
\hline Cement $+0.5 \%$ Hexamine (by weight of cement) & S-III \\
\hline Cement $+0.5 \%$ Calcium nitrite (by weight of cement) & S-IV \\
\hline
\end{tabular}

Table 1: The analysis of the inhibiting systems.

\begin{tabular}{|c|c|}
\hline Sample Notation & Consistency (\%) \\
\hline S-I & 34 \\
\hline S-II & 34 \\
\hline S-III & 32 \\
\hline S-IV & 33 \\
\hline
\end{tabular}

Table 2: Consistency of cement.

\begin{tabular}{|c|c|c|c|}
\hline \multirow{2}{*}{$\begin{array}{l}\text { Sample } \\
\text { Notation }\end{array}$} & \multicolumn{2}{|c|}{ Distance between indicator points in $\mathrm{mm}$} & \multirow{2}{*}{$\begin{array}{c}\text { Expansion in } \\
\mathrm{mm}\end{array}$} \\
\hline & Before Boiling & After Boiling & \\
\hline S-I & 37 & 38 & 1 \\
\hline S-II & Disintegrated & Disintegrated & Disintegrated \\
\hline S-III & 29 & 30 & 1 \\
\hline S-IV & 31 & 32 & 1 \\
\hline
\end{tabular}

Table 3: Soundness.

\begin{tabular}{|c|c|c|c|c|}
$\begin{array}{c}\text { Sample } \\
\text { Notation }\end{array}$ & $\begin{array}{c}\text { Initial Setting time } \\
\text { in minutes }\end{array}$ & $\begin{array}{c}\% \\
\text { Variation }\end{array}$ & $\begin{array}{c}\text { Final Setting time } \\
\text { in minutes }\end{array}$ & $\begin{array}{c}\% \\
\text { Variation }\end{array}$ \\
\hline S-I & 90 & & 180 & \\
\hline S-II & 349 & 287.77 & 1500 & 733.33 \\
\hline S-III & 135 & 50 & 315 & 75 \\
\hline S-IV & 160 & 77.78 & 450 & 150 \\
\hline
\end{tabular}

Table 4: Setting time.

\begin{tabular}{|c|c|c|c|}
\hline \multirow{2}{*}{ Sample } & \multicolumn{3}{|c|}{ Compressive strength in $\mathbf{~} / \mathbf{m m}^{\mathbf{2}}$} \\
\cline { 2 - 4 } & Avg. 3 days & Avg. 7 days & Avg. 28 days \\
\hline S-I & 28.15 & 34.96 & 44.01 \\
\hline S-II & $\begin{array}{c}\text { Distortion during } \\
\text { demolding }\end{array}$ & $\begin{array}{c}\text { Distortion during } \\
\text { demolding }\end{array}$ & $\begin{array}{c}\text { Distortion during } \\
\text { demolding }\end{array}$ \\
\hline S-III & 25.75 & 32.63 & 38.80 \\
\hline S-IV & 24.53 & 31.27 & 40.56 \\
\hline
\end{tabular}

Table 5a: Compressive strength of cement and inhibited cement.

\begin{tabular}{|c|c|c|c|c|}
\hline \multirow{2}{*}{ Sample } & \multicolumn{4}{|c|}{ Compressive strength in N/mm } \\
\cline { 2 - 5 } & $\mathbf{7}$ days & $\mathbf{2 8}$ days & $\mathbf{9 0}$ days & $\mathbf{1 2 0}$ days \\
\hline S-I & 29.54 & 37.93 & 48.50 & 50.70 \\
\hline S-II & $\begin{array}{c}\text { Disintegrated } \\
\text { during } \\
\text { curing }\end{array}$ & $\begin{array}{c}\text { Disintegrated } \\
\text { during } \\
\text { curing }\end{array}$ & $\begin{array}{c}\text { Disintegrated } \\
\text { during } \\
\text { curing }\end{array}$ & $\begin{array}{c}\text { Disintegrated } \\
\text { during } \\
\text { curing }\end{array}$ \\
\hline S-III & 22.16 & 34.83 & 46.60 & 49.40 \\
\hline S-IV & 22.22 & 33.81 & 45.07 & 48.70 \\
\hline
\end{tabular}

Table 5b: Compressive strength of concrete.

3 samples, (S-II, S-III, S-IV) with respect to S-I, it is observed that, the initial setting time is increased by $287.77 \%$ in S-II followed by $50 \%$ in S-IV and $77.78 \%$ in S-III. The variation in final setting time with respect to S-I is increased by $733.33 \%, 75 \%$ and $150 \%$ in S-II, S-III and S-IV respectively. It is believed that inhibitor retarded the rate of reaction of tri-calcium aluminates with water (i.e., hydration process) (Table 4).

Compressive strength test on both cement and concrete: The results of compressive strength test on both cement and concrete systems carried out under laboratory conditions are given in Tables $4 \mathrm{a}$ and $4 \mathrm{~b}$. It is observed that addition of hexamine(S - III) and calcium nitrite(S - IV), a reduction in the value of compressive strength has been observed as compared to control specimen. Though with increase in curing period, an increase in compressive strength has been observed but the values remain lower than the corresponding values of control specimen. It is also observed that inhibited concrete with combination of sodium citrate and calcium nitrite (S-II) disintegrated at the time of curing (Tables 5a and 5b).

Corrosion inhibition test: Table 6 shows loss of weight of 
Citation: Quraishi MA, Nayak DK, Singh BN, Kumar V, Pandey KK (2016) Experimental Studies on Effects of Sodium Citrate, Calcium Nitrite and Hexamine as Corrosion Inhibitor in Concrete. J Steel Struct Constr 2: 117. doi: 10.4172/2472-0437.1000117

embedded steel in different systems after 90 days (i.e., initially cube was immerged in the water having a $\mathrm{pH}$ value of 3.5 - 4.5 for 90 days and then placed in dry conditions for the next seven days). Corrosion efficiency for S-III and S-IV were compared with respect to S-I for curing period of 90 days and it was observed that the corrosion efficiency of both S-III and S-IV was more. However increase in S - III was higher than that of the S - IV (Table 6).

Photographic and petrographic study: The photographic examination of steel was observed in two cases:

(1) absence of hexamine and calcium nitrite and (2) presence of hexamine and calcium nitrite that are shown in following Figures 1-5. It is observed that inhibited steel surface is smoother as compared the blank sample (Figures 1-5).

Under the petrological microscope, it is observed that the microcracks, voids and carbonation are dominant in the plain cement concrete samples (Figures 6-8) in comparison to concrete sample with corrosion inhibitors. The blank samples are highly porous (Figures 6 and 8) in comparison to inhibited samples. The mineral grains in blank samples are highly fractured and in-filled with cementitious materials.

\begin{tabular}{|l|c|c|c|c|}
\hline \multirow{2}{*}{ System } & \multicolumn{2}{|c|}{$\begin{array}{c}\text { Average weight reduction } \\
\text { (mg) }\end{array}$} & \multicolumn{2}{c|}{ Inhibition Efficiency (\%) } \\
\cline { 2 - 5 } & 90 days & 180 days & 90 days & 180 days \\
\hline Cement (S-I) & 45.32 & 80.12 & & - \\
\hline $\begin{array}{l}\text { Cement + 1\% SC + } \\
1 \% \text { CN (S-II) }\end{array}$ & - & - & - & 43.52 \\
\hline $\begin{array}{l}\text { Cement+ .5 } \\
\text { Hexamine (S-III) }\end{array}$ & 24.92 & 42.25 & 45.01 & 25.74 \\
\hline $\begin{array}{l}\text { Cement + .5 Calcium } \\
\text { nitrite (S-IV) }\end{array}$ & 34.58 & 59.50 & 23.69 & \\
\hline
\end{tabular}

Table 6: Reduction of weight in different samples of Steel bars after 90 and 180 days.

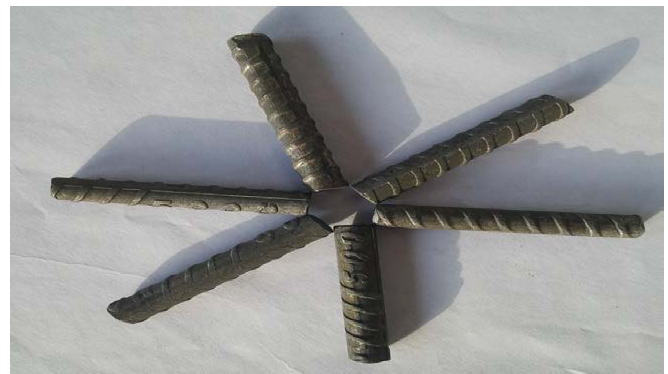

Figure 1: Shows corrosion of steel bar embedded in the blank sample after 90 days of exposure.

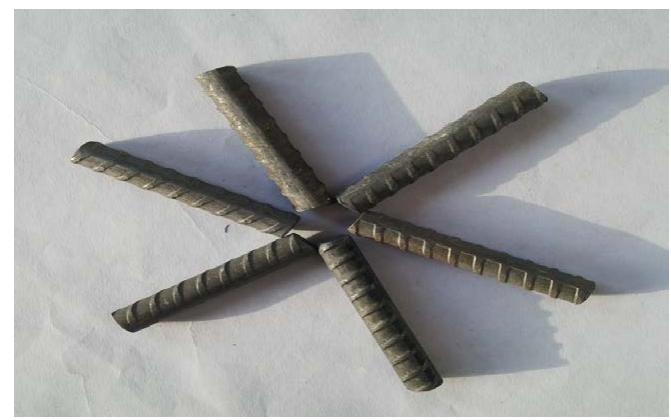

Figure 2: Steel embedded in concrete with $0.5 \%$ of hexamine after 90 days exposure.

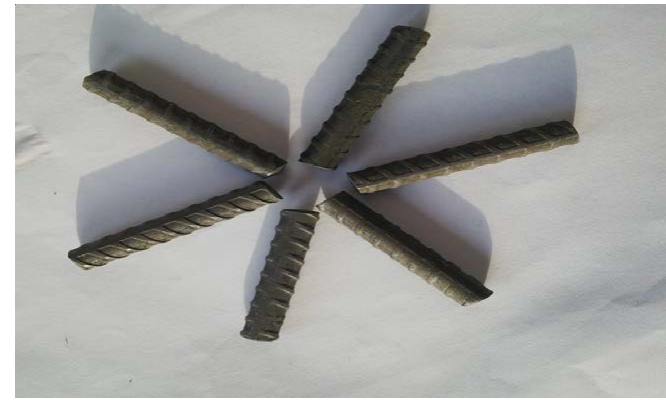

Figure 3: Steel embedded in concrete with $0.5 \%$ of calcium nitrite after 90 days exposure.

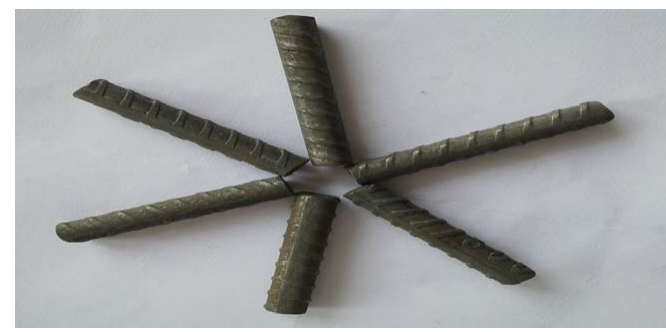

Figure 4: Steel embedded in concrete with $0.5 \%$ of hexamine after 180 days exposure.

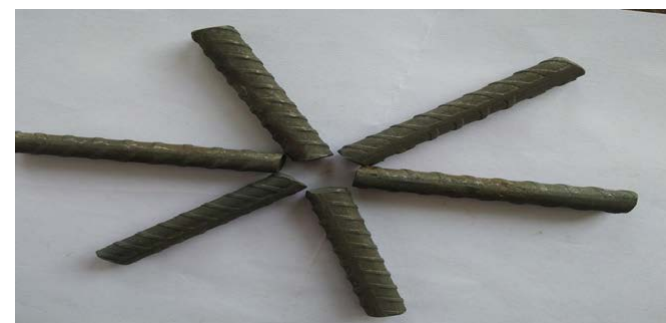

Figure 5: Steel embedded in concrete with $0.5 \%$ of calcium nitrite after 180 days exposure.

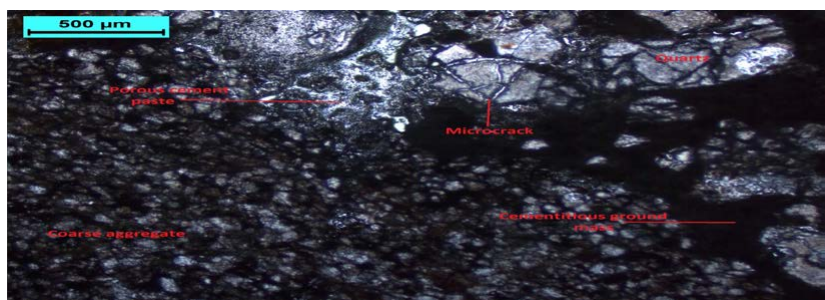

Figure 6: Photomicrograph showing coarse aggregates and medium to coarse grained quartz enclosed within the groundmass of the controlled sample at 90 days. Also notice porous cement paste and microcracks running across and periphery of the quartz grain (O.L.).

Most of the coarse aggregates and minerals boundary show irregular or corroded contact with cementitious material in the blank samples (Figures 6 and 8). It was noted that microcracks and voids were less in 180 days blank sample in comparison to 90 days blank sample. Intensive carbonation is observed in the blank samples (Figure 2.2.). However, it is less prominent in the samples with corrosion inhibitors (Figures 6-8).

Mechanism of corrosion Inhibition: The microcracks and voids 


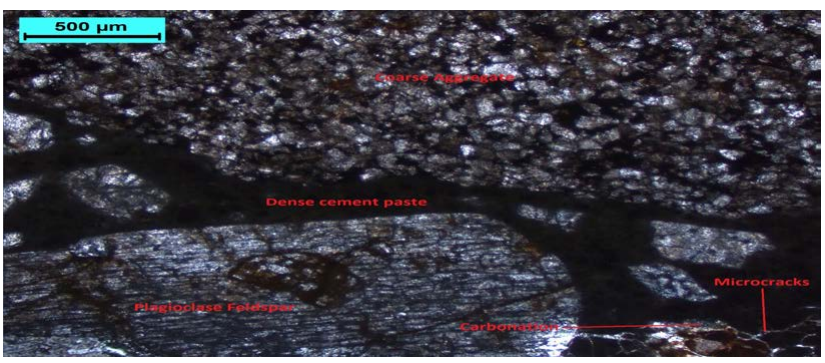

Figure 7: Photomicrograph showing presence of microcracks and carbonation in the blank sample at 90 days. Also notice coarse aggregates showing corroded and sharp contact with cementitious ground mass (O.L.).

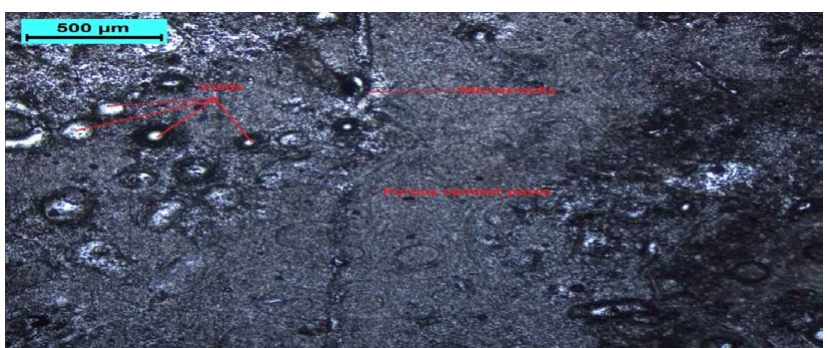

Figure 8: Photomicrograph showing presence of voids and microcracks in the blank sample at 90 days. Also notice porous cement paste (O.L.)

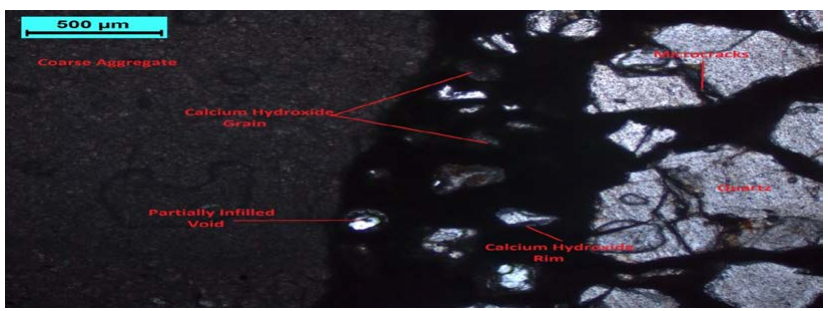

Figure 9: Photomicrograph showing presence of infilled microcrcks and partially infilled voids in the concrete sample with hexamine corrosion inhibitor (90 days). Also notice formation of calcium hydroxide grains, and calcium hydroxide rims around quartz grains present within the dense ground mass. Coarse aggregates also showing sharp contact with cementitious groundmass (O.L.)

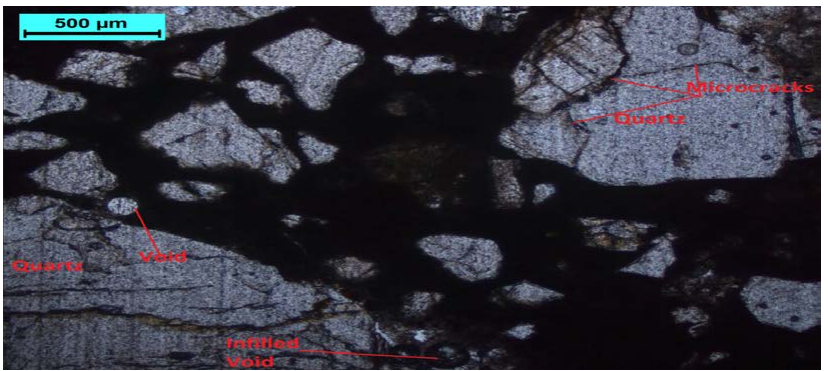

Figure 10: Photomicrograph showing presence of voids and fully infilled voids in the concrete sample with hexamine corrosion inhibitor (180 days). Also notice that cracks within the coarse mineral grains are infilled with cementitious materials (O.L.).

of concrete samples with corrosion inhibitors are in-filled (fully or partially) with C-S-H Gel or cementitious materials (Figures 9-12). Hexamine and calcium inhibits corrosion by blocking the pores of the

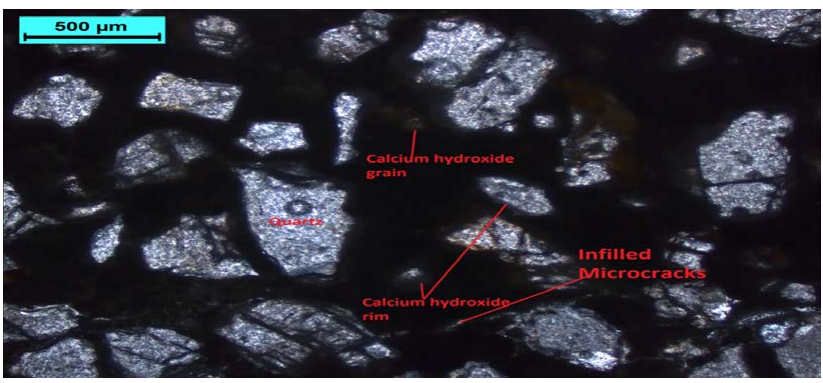

Figure 11: Photomicrograph showing infilled microcracks, and calcium hydroxide present in the concrete sample with calcium nitrite 90 days. Also notice the formation of calcium hydroxide rims around the mineral grains (O.L.)

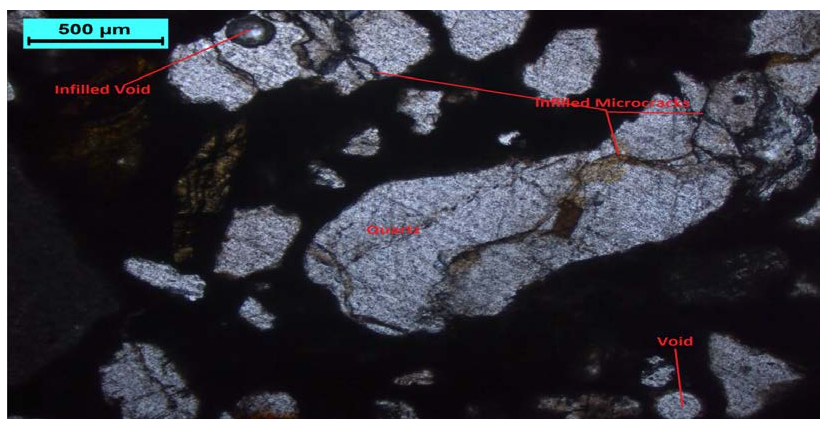

Figure 12: Photomicrograph showing presence of infilled microcracks and infilled voids within the calcium nitrite corrosion inhibitor (180 days) (O.L.).

surface of the steel, thereby reducing the ingress of $\mathrm{Cl}^{-}, \mathrm{CO}_{2}$, moisture and other aggressive agents.

\section{Conclusion}

The compressive strength of concrete decreases with the addition of inhibitors as observed at various curing intervals. However, with the increase in curing period the difference in compressive strength of inhibited concrete and blank sample reduces. Since the corrosion efficiency of hexamine and calcium nitrite increases by $45 \%$ and $25 \%$ respectively in case of inhibited concrete, blank sample has less resistance to corrosion. Sodium citrate prevents the hydration of cement and it is not suitable as an inhibitor. The voids and microcracks are dominant in the blank samples as compared to the inhibited concrete samples.

\section{References}

1. CIP 25- corrosion of steel in concrete. Technical information prepared By NRMCA (National Ready Mixed Concrete Association).

2. Mohammed TU, Otsuki N, Hamada H (2003) Corrosion of steel bars in cracked concrete under marine environment. J Mater Civ Eng 15: 460-469.

3. Ngala VT, Page CL, Page MM (2002) Corrosion inhibitor systems for remedial treatment of reinforced concrete. Part 1: calcium nitrite. Corros Sci 44: 2073 2087

4. Montes P, Bremner TW, Lister DH (2004) Influence of calcium nitrite inhibitor and crack width on corrosion of steel in high performance concrete subjected to a simulated marine environment. Cement Concrete Comp 26: 243-253.

5. Mailvanam IP (2004) The chemistry of corrosion inhibitor. Cement Concrete Comp 26: 179

6. Chung L, Kim JHJ, Yi ST (2008) Bond strength prediction for reinforced concrete members with highly corroded reinforcing bars. Cement Concrete Comp 30: 603-611. 
Citation: Quraishi MA, Nayak DK, Singh BN, Kumar V, Pandey KK (2016) Experimental Studies on Effects of Sodium Citrate, Calcium Nitrite and Hexamine as Corrosion Inhibitor in Concrete. J Steel Struct Constr 2: 117. doi: 10.4172/2472-0437.1000117

Page 5 of 5

7. Gaidis JM (2004) Chemistry of corrosion inhibitors. Cement Concrete Comp 26: 181-189.

8. Mishra DMB, Mann DS (2000) Corrosion mitigation measures in design of reinforced concrete. The Indian Concrete Journal 74: 177-179.

9. Batis G, Routoulas A, Rakanta E (2003) Effects of migrating inhibitors on corrosion of reinforcing steel covered with repair mortar. Cement Concrete Comp 25: 109

10. Morris W, Vico A, Vazquez M (2003) The performance of a migrating corrosion inhibitor suitable for reinforced concrete. J Appl Electrochem 33: 1183.

11. Saricimen H, Mohammad M, Quddus A, Shameem M, Barry MS (2002) Effectiveness of concrete inhibitors in retarding rebar corrosion. Cement Concrete Comp 24: 89

12. Ngala VT, Page CL, Page MM (2003) Corrosion inhibitor systems for remedial treatment of reinforced concrete. Part 2: sodium monofluorophosphate. Corros Sci 45: 1523-1537.

13. Quraishi MA, Kumar V, Abhilash PP, Singh BN (2011) Calcium stearate: a green corrosion inhibitor for steel in concrete environment. J Mater Environ Sci 2: 365.

14. Singh A, Singh VK, Quraishi MA (2010) Effect of fruit extracts of some environmentally benign green corrosion inhibitors on corrosion of mild steel in hydrochloric acid solution. J Mater Environ Sci 1: 162-174.

15. Kahraman R, Saricimen H, Al-Zahrani M, Al-Dulaijan S (2003) Effect of inhibitor treatment on corrosion of steel in a salt solution. $\mathrm{J}$ of Materi Eng and Perform 12: $524-528$

16. Plain and reinforced concrete-code of practice. IS 456-2000, Indian Standard Institute, New Delhi.

17. Methods of physical tests for hydraulic cement. IS 4031 (Part 4)-1988, Indian Standard Institute, New Delhi.

18. Methods of physical tests for hydraulic cement. IS $8112-198943$, Bureau of Indian Standards, New Delhi.

19. Methods of physical tests for hydraulic cement. IS 4031 (Part 3)-1988, Indian Standard Institute, New Delhi.

20. Standard sand for testing cement-specification. IS 650-1991, Indian Standard Institute, New Delhi.

21. Methods of physical tests for hydraulic cement. IS 4031 (Part 6)-1988, Indian Standard Institute, New Delhi.

22. Jana D (2005) 10th Euroseminar on Microscopy Applied to Building Materials, Scotland.

23. Singh BN, Asha K, Kumar V (2007) Indian Public Finance and the Twelfth Finance Commission. The Reasercher. pp: 55.

24. Jepsen BB, Christensen $P$ (1989) Calcium stearate: a green corrosion inhibitor Bull Int Assoc Eng Geol No 39. 